\title{
LA MÚLTIPLE MIRADA. EL CUENTO Y LOS PERSONAJES FEMENINOS EN ELENA PONIATOWSKA
}

\author{
LILIANA PEDROZA
}

Soy tu mujer de siempre, la diurna, la nocturna, soy tu mujer cotidiana, la del pan y los higos. Soy la que conoces. ¿Qué quieres descubrir?

«La banca»

Elena Poniatowska

Referirse a Elena Poniatowska es señalar a muchas mujeres muy distintas entre sí. El territorio que descubre cuando escribe va delineando una serie de rostros, de perfiles femeninos disímiles, rasgos de personalidad que se cruzan, que se confrontan, que se polarizan, o simplemente tienden a la ruta de una pasiva divergencia.

Caminar por su narrativa, y aún sólo por sus cuentos, es andar por pasajes conocidos y desconocidos, por vericuetos y por laberintos en los que uno no sabe cómo llegó ni tampoco cómo se saldrá. Cada historia contada a través de ella es un espejo que se suma a un cuarto con cientos de espejos reflejando como acto ilusorio el infinito. Y es que ella, Elena, es infinita.

Las voces que acechan y visten cada relato, que circulan y circundan la imaginación de Elena en su hechizo por contar, son de mujeres ásperas pero también dulces, débiles y fuertes, jóvenes y viejas, quietas y turbulentas; todas ellas emanando de un contraste fascinante, de la misma frontera que impone el salto de un libro de cuentos a otro.

Uno, De noche vienes, muestra personajes con vigor, con fuerza, con énfasis en el carácter y el temple, como si de un trazo grueso en una figura dibujada se tratara; en cambio el otro, Tlapalería, contiene personajes suavemente delineados, mujeres que recuerdan, que añoran lo vivido, que se arrepienten de ello, o que simplemente rememoran: madres, hijas, abuelas; la evocación del pasado juega un papel importante en el acto de narrar. Los personajes desde dentro de sí, cuentan, se cuentan, nos cuentan un trozo, un fragmento, un relámpago de memoria como necesidad principal en ese intento de reordenar su mundo interior de pensamientos y deseos. Pasividad y actividad oscilan en los personajes entre una obra y otra. La primera mencionada, publicada en 1979, la segunda en 2003.

Es interesante poder apreciar la evolución y la transformación en los personajes femeninos dentro de una obra y otra con más de veinte años de distancia entre ambas. Puestos en un panorama general y a golpe de vista serán el pasado y el futuro los elementos que confluyan como motor interno dentro de los cuentos, ya que, en la primera etapa los personajes aguardan o accionan sobre un presente o un futuro inmediato; en la segunda, es el rescate del pasado lo que genera la historia.

En el caso del libro De noche vienes personajes como Manuela en «La ruptura» o Esmeralda en el cuento que da título a la obra, cándidos y dóciles al principio, van desvelando un roce de dominación en sus actos, se guardan quietos a la caza, incluso, se dejan cazar dentro de esa oscilación que los lleva de nuevo a la inocencia y la ternura.

- Manuela, eres tan torpe como un pájaro que trata de volar, ojalá ya aprendas. Si sigues así, tus palabras
Liliana Pedroza

Narradora y crítica, realizó sus estudios de doctorado en la Universidad Complutense. Ha estudiado la obra de las narradoras mexicanas, con especial atención a Elena Garro, de quien ha publicado recientemente: Andamo huyendo Elena (2007), obra en la que también está presente Elena Poniatowska. 


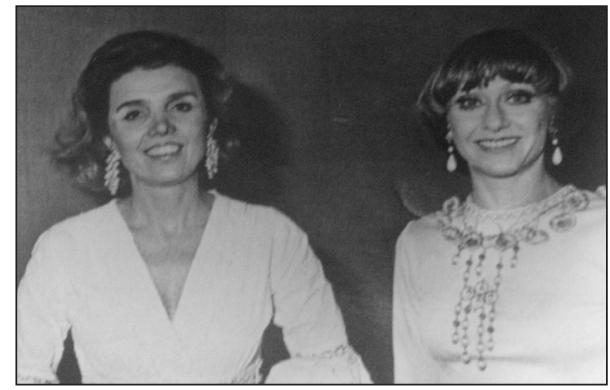

no serán racimos de uvas sino pasas resecas de la virtud.

- Es que los besos son raíces, Juan¹.

Pero ya Manuela había vislumbrado su presa y, coleccionista de objetos y manías, introdujo un tigre dentro de su colección: un hombre con piel rayada con el que ella espera ser rasgada por fin o, mejor aún, devorada («le pondría un collar y una cadena»). Pero el tigre deja de bramar y se convierte en un gato frenElena Poniatowska, De noche vienes, México, Era, 2000, p. 14

2

Ibid., p. 159

3

Ibid., p. 21.

4

Ibid., p. 22.

5

Ibid., p. 70.

La múltiple mirada. El cuento los personajes femeninos en Elena Poniatowska

LILIANA PEDROZA te a sus fauces, un animal indefenso que ansía leche en lugar de carne. Manuela desespera y es ella quien devora al final.

Esmeralda también colecciona hombres, pero ella es mucho más entusiasta en su haber, ya que tiene cinco maridos. El cuento se desenvuelve dentro de una oficina del Ministerio Público, Esmeralda es acusada de poligamia y el delito, para quien se encarga de juzgarla, es asumido con una gran gravedad ya que la ciudadana ha atentado contra la moral y las bases de la familia, ha engañado a hombres, a la sociedad, y hasta a los principios de la Revolución Mexicana. Aquí habría que hacer un paréntesis y decir que los personajes masculinos comentan entre sí que han visto casos similares en hombres, pero nunca en una mujer, y eso es precisamente lo que no se debe permitir.

Loca, animala, tarada, todas las mujeres están locas, son unas viciosas, unas degeneradas, dementes, bestias, mira que meterse con cinco a la vez y amanecer como la fresca mañana, porque a esta mujer no le hacen mella tantas y tantas noches de guardia, ni le llega nada de lo que le digo, por más que me empeño en encauzarla, en hacerla comprender ${ }^{2}$.

La ingenuidad de Esmeralda y esa virtud de darse a los demás la mantendrá salva de la situación de la que es completamente inconsciente. Ya que, por qué no haber estado con los cinco si los cinco la necesitaban.

"Canción de cuna», así como «Esperanza número equivocado» son relatos irónicos de mujeres en espera o al acecho de un hombre. «Canción de cuna» por su parte es un instructivo mordaz en el que la autora, con una sonora carcajada, señala los pasos a los que debe ser guiada toda señorita, aunque le advierte hay «moros en la costa azul del cielo». Para sus deseos nocturnos en soledad sólo tiene su almohada blanca como escudo. deje de tejer «al pie de la ventana» cuando no
En «Esperanza número equivocado» la ironía en Elena se vuelve más aguda marcando la obsesión por casarse, la angustia de quedarse atrás en esa carrera que significa 'atrapar' a un hombre. Esperanza abre con rencor, con envidia, con anhelo en ocasiones, el periódico para mirar la página de sociales donde se encuentran los enlaces matrimoniales.

...examina, infatigable, los rostros de cada una de las felices desposadas. Mire, a esta le va a ir de la patada... A esta otra pue que y se le haga... Esta ya se viene fijando en otro. Ya ni la amuela. Creo que es el padrino... Sigue hablando de las novias, obsesiva y maligna ${ }^{3}$.

Esperanza ha cursado cien novios buscados en los números telefónicos equivocados. «Su afición al teléfono la hacía entablar largas conversaciones» pero de tantos se quedó sin ninguno, aunque no perdía la ilusión de que un día alguien de pronto por un azar se equivocara en los números que ha marcado y le diga «como Pedro Infante ¿Quiere usted casarse conmigo?». Pasaron 30 años sobre ella -los mejores de su vida- y ya su voz, cansada, no se le escucha al teléfono. Ahora, cada vez que un hombre equivoca las cifras ella responde: «No señor, no, no soy Isabel Sánchez, y por favor, se me va a ir usted mucho a la chingada» ${ }^{4}$.

En «Canto quinto» el personaje es una mujer que ama, que intenta apresar el momento de los amantes, pero ese instante ya se ha ido para el hombre porque siempre se está siendo tarde para marcharse. El futuro es la pieza de un departamento en alquiler que no pueden pagar, el amor siempre está de paso en el cuarto de un hotel barato en el que al salir de él sólo queda soledad. Como en «La felicidad», un intento de detener el acto amoroso, el acto que se escapa en cuanto surge. La felicidad es fugaz pues el otro se ha ido con el sueño, con el pensamiento que se traslada a otra parte.

Dime qué piensas, mi amor, dime en qué estás pensando, ahorita, pero ahorita que te quedaste así contigo solo, olvidándote de que estoy aquí contigo, mi amor, en qué estás pensando, siempre pregunto lo mismo, ¿̇me quieres? te estás quedando dormido [...] y ya no me perteneces, y no me llevaste contigo, me dejaste atrás... ${ }^{5}$.

El personaje de «Inventario» es, a mi parecer, el que tiene más fuerza, más vigor dentro del libro, es en quien pesa más su identidad, su 
presente, su propia historia a pesar de la carga antepuesta. En la historia, la mujer manda llamar a una bodega para desocupar su casa de muebles antiguos, los que han habitado durante generaciones. Los muebles hablan, dicen, cuentan, son familia también, hacen compañía.

Toda mi vida he estado prendida a esos muebles, invadieron mi alma como antes invadieron la de mi abuela y la de mis tías [...] Se están llevando la primera capa de mi piel, caen las escamas 6 .

Pero esa misma presencia se vuelve tirana al convertirse también en la materialización de los recuerdos de los demás, en el peso de generaciones anteriores con sus miedos y sus frustraciones. Por eso ella piensa:

¡Qué no me legaran todos sus recuerdos! ¡Qué no me pasaran su costal de palabras muertas, sus actos fallidos, sus vidas inconclusas, sus jardines sin gente, sus ansias, sus agujas sin hilo, sus bordados que llevan de una pieza a otra, sus letanías inhábiles!?.

Los muebles en el momento de la partida cobran vida, hay un momento de dubitación, pero el acto de abandonarlos ya está hecho. El personaje queda vacío, pero ese espacio desocupado le pertenece sólo a ella.

En «La casita de sololoi», Laura es una mujer que apremia el futuro, uno promisorio en el que se revelan todas sus cualidades. «Sin duda alguna, había que irse para triunfar, salir de este agujero, de la monotonía tan espesa como la espesa sopa de habas que tanto le gustaba a Beto»8. Agotada por sus circunstancias, se dará cuenta de que ha hipotecado su vida por algo que detesta. Se ha convertido en un guiñapo, un títere al mando de sus hijos, pequeños tiranos que invadieron su casa. La familia que ha formado tira de las cuerdas en las que ella obedece cansada, sin voluntad.

En «Métase mi prieta, entre el durmiente y el silbatazo» el personaje femenino adquiere dimensiones insospechadas, al contrario de las otras protagonistas, Teresa es vista a través de la voz de un hombre, su amante. Ella, evocada en proporciones desmesuradas, generosa en carnes y ávida de sexo, será también el motor de la narración. La relación que tiene el maquinista con su tren, será parecida a la que tiene con su mujer, el trato es el mismo, la pasión con una y otro es similar, mujer y tren es lo mismo, a los dos se monta, los domestica, los acaricia, los lubrica, les saca sus olores y sus propios quejidos, va acomodando la mano en cada una de las partes hasta que quede la huella de su presencia.

Pancho se instala en el asiento, agarra la palanca y al hacerlo la acaricia, mientras le transmite una orden. Cuando la máquina suelta el vapor con un ruido de agua que sale a gran presión, Pancho también se relaja, y se tensa como cable al meter los frenos...

[...]

A la Teresa también le complacía que él fuera acariciándola poco a poco, suavizándola, tallándole, metiéndole la mano en los menores intersticios hasta sacarle su aceitito, sus juguitos blandos?.

Y sin duda, Tlapalería pertenece a otra etapa de la autora, ya que si en De noche vienes hay una mayor presencia del narrador que discurre, que se entromete, carga el peso de la historia en cuanto a lo que el autor/narrador piensa. La ironía, el compromiso con lo dicho dimensiona los relatos. En cambio, Tlapalería es un libro que tiene sobre todo el gusto por contar, por narrar lo que ha ocurrido ya, no las posibilidades de otros sucesos (a diferencia de De noche vienes, que siempre se mira el futuro como promesa). En este libro, Tlapalería, Elena deja que las historias corran su suerte valiéndose de sí mismas. No existe la subversión del otro, sin embargo tiene el encanto de lo que se narra.

En el cuento «El corazón de la alcachofa» el rito impuesto a la hora de comer una vez por semana este vegetal revela mucho de cada miembro de la familia. La abuela da inicio a la ceremonia que ello implica. Las hojas se van tomando poco a poco, con meticulosidad, saboreando cada una de ellas, se va bordeando el centro hasta descubrirlo, hasta llegar al corazón de la alcachofa.

Cada uno tiene su propia relación con la alcachofa y su vida también se refleja en ella. Hay quien la come de prisa o quien desprecia las hojas en un suave vaivén entre el plato y la boca, mostrando la indefensión de la planta en el aire. La abuela aunque pudorosa «siempre andaba mostrando su corazón», en cambio la madre pensaba que «la vida [igual que a una alcachofa] la ha despojado de todas sus hojas y le ha dejado el corazón al descubierto» ${ }^{10}$. La narradora también tiene semejanza con el vegetal, pues el corazón, el de ella misma, es como el de una alcachofa, rodeado de hojas más altas que ella.

En «La banca» el personaje rememora igualmente, ya que con un juego de narradores, va desde el inicio a una infancia con criadas y los momentos claves que la inician
6 lbid., p. 57.

7 Ibid., p. 63.

8 lbid., p. 97.

9

lbid., pp. 113 y 116.

10

Poniatowska, Tlapalería, México, Era, 2003, p. 55.

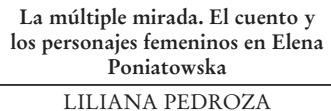




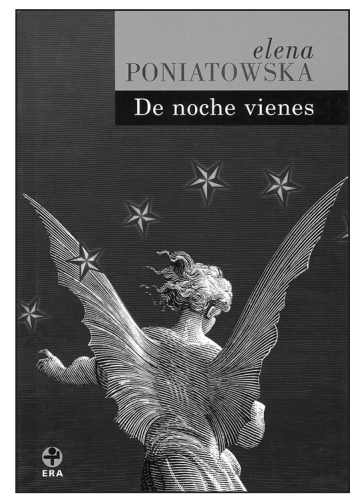

11

Poniatowska, De noche vienes, op. cit., p. 41.

12

Poniatowska, Tlapalería, op. cit., p. 91.

13 Ibid., p. 63.

La múltiple mirada. El cuento y los personajes femeninos en Elena Poniatowska

LILIANA PEDROZA al amor. En la segunda toma, pues el relato es como un viso cinematográfico, la protagonista es una mujer despuntando en la vida adulta y se retoma el reencuentro con la criada, con el suceso en que se destruye su pareja a causa de ella, y finalmente en el recuerdo de un pasado remoto pues quien narra ve los hechos a gran distancia. Recuerda a la misma mujer (a la criada) en dos etapas distintas que han marcado su vida.

En «Chocolate» los personajes son suavemente delineados con fondo de perro. La abuela, un personaje constante en Elena Poniatowska, como cuidadora, guiadora al cielo de tantos perros que encontró, se ve envuelta en una relación especial con el perro de un pordiosero. La voz narrativa, una muchacha de dieseis años, es también un canino para su abuela. El fondo, los personajes, la acción gira en torno a ellos y también la relación se nutre a partir de ellos. La narradora sólo aspira a ser para la abuela «la perra más consentida, la cachorrita de hocico húmedo».

«Canarios» es de nuevo la obsesión del sujeto nombrado con lo estrechamente vinculado. Uno de los dos canarios de la protagonista ha volado y ella no sabe qué hacer. El canario que ha quedado es frágil, delicado. De pronto un día comienza a cantar y ella inaugura el día, inaugura la casa que canta a partir de ese momento. El canario es pequeño pero ha agitado a un árbol, el árbol es ella, y resuena porque es de madera. El día inaugurado le dice que el canario es su corazón, entonces canta.

Uno de los temas que confluye en ambos libros es en el punto de relación de las protagonistas con sus sirvientes, con esa parte contraria, con ese otro mundo al cual no pertenece. Pero en sus cuentos la relación es muy particular, ese otro mundo al que no le es posible entrar a los personajes principales se vuelve sórdido, confuso, desordenado. En las historias, el punto que podría ser de conexión las devuelve a cada una a su sitio, tan alejadas la una de la otra. En «El limbo» la protagonista no es capaz de concebir cómo su empleada ha echado al mundo y abandonado a su hijo como si de una función fisiológica diaria se tratara mientras que en el área superior de la casa sabe que hay quienes

se acomodaban alrededor [de la abuela] entre pequeños sillones, frente a las cortinas de organdí y decían cosas bonitas, blancas y leves, acerca de los sucesos del día para despedirlos entre los ramos de flores, el olor de los pétalos de rosa que la abuela ponía a secar y la colcha blanquísima tejida por manos calladas y diligentes ${ }^{11}$.

En «Love Store», Teleca vive una relación de dependencia con su sirvienta, la soledad de la protagonista ha hecho volcar toda su atención en ella, que es presentada como una figura grotesca. Aquí los roles han cambiado, no se sabe quién domina a quién. Sin embargo, y pese a todo, la muchacha toma su derecho a la libertad y desaparece. Teleca queda derrotada y sola.

En «La banca» y «Coatlicue» ocurre lo mismo, la intromisión de estos personajes bizarros crean un desorden en la vida de las protagonistas, una destroza la vida conyugal del ama y la otra irrumpe casi de manera sobrenatural trastornando la salud mental y las circunstancias que rodean al personaje. Son figuras fuertes que se sostienen en la memoria como una persecución delirante. Estas figuras extrañas no encajan en su orden de vida.

Lo que yo escuchaba adquiría un aspecto bestial e inesperado porque lo asimilaba mi status burgués, mi desarraigo, yo, descendiente de catedrales y santos de cantera. Alguna vez había declarado que lo prehispánico me era ajeno ${ }^{12}$.

Las historias que convergen entre un libro y otro, una constante más allá de sus cuentos y que roza otra parte de su narrativa tiene que ver con las protagonistas en un tiempo de espera, una pasividad que dentro de ellas se vuelve acción. En el caso de «El recado", el personaje aguarda la llegada de un hombre a la puerta de su casa y comienza a rememorarlo, ella viste su vida a partir de él, de lo que acontece a partir de él. El hombre no aparece, es por eso que ella desaparece igualmente de escena, la acción ocurre en ese estado de expectación. Lo mismo sucede en «La jornada» en el que ella es semilla y él es raíz, y cómo se va percatando de que la raíz va envolviendo a la semilla hasta dejarla atrapada por completo. Ella es un carrizo por donde el hombre sopla y saca un dulce sonido. El carrizo no es nada si no hay quien lo tome y lo toque. $\mathrm{O}$ en el caso de «El rayo verde», una mujer que espera durante toda su vida vislumbrar el instante, un instante de luz justo al amanecer y que es la felicidad. Y en el caso de «Los bufalitos» en el que la maestra Roberta «tiene miedo de que se le vayan los sentimientos, las sensaciones, los encuentros, los trenes» ${ }^{13}$. Existe un grado de dependencia entre los personajes, un aspecto de debilidad que en el segundo libro es 
mucho más evidente pues ya hay dos historias en las que los personajes se preguntan si no han sido un error sus vidas. Su existencia es cifrada en la búsqueda, en la permanencia de la felicidad, en la aprobación del otro, en el encuentro con el sujeto amado, en el estado que las libere de la soledad.

Te necesito, eres necesario, eso es, eres necesario y lo sabes, hombre necesario que casi nunca dices mi nombre ${ }^{14}$.

[Ella] Es huidiza, inasible, nunca deja que la toque, que la abrace. ¿Qué voy a hacer sin ella, en medio de esta soledad aterradora? ${ }^{15}$.

Las formas de búsqueda que realizan en ambas obras son distintas, sus preguntas son formuladas de manera diferente pero todas llegan al mismo punto, el discurso de las protagonistas cambia, se vuelve a veces rebelde, otras sumiso, pero convergen todas en una necesidad de reconocimiento en el otro, en ver su rostro y su cuerpo reflejado en el espejo de quien mira, necesita ser mirada por el otro, por eso a veces grita y otras calla.

El principal matiz que varía entre un libro y otro, De noche vienes y Tlapalería es, a mi parecer, la voz de quien narra. En el primero se nota una escritora más aguerrida, más audaz con lo que escribe y tomando más posición con lo que denuncia. La risa sonora en la ironía, la burla, la denuncia están más expuestos en cada historia narrada. Se nota clara la presencia de una autora que escribe sobre algo que la oprime, que la aqueja, que se cuestiona y que cuestiona al lector. Es enérgica. En cambio, en Tlapalería, las historias devienen sin tanto ruido, son historias contadas desde la remembranza, los personajes son aún más frágiles, son construidos a partir de la memoria y desde allí se extraen. Hay que tener cuidado porque la memoria los deja caer y se desmoronan en el acto fallido de ser llevados al presente. Aquí el verbo conjugado a fin de cuentas es en pasado. Las acciones ya ocurrieron y es cuando viene el cuestionamiento de haber equivocado o no su accionar en la vida, en su única vida.

Así, mujeres lacias, volátiles, libélulas, mujer brasa, semilla, árbol, canario, muchachito atrabancado, precipitada y nunca prudente; niña rubia de pelos enmarañados con sueños $y$ pesadillas enredados en sus pestañas ${ }^{16}$, se nos presentan en forma de cuento de Elena Poniatowska.

Elena se camufla para perdernos por los laberintos de su amplio territorio interior, de sus múltiples miradas. Y aún así, ella es capaz de preguntar, de preguntarnos: «¿Qué es lo que quieres descubrir?». Poniatowska, De noche vienes, op. cit., p. 66.

15

Ibid., p. 122

16

Adjetivos con los que Elena Poniatowska califica a sus personajes en De noche vienes y Tlapalería.
La múltiple mirada. El cuento y los personajes femeninos en Elena Poniatowska

LILIANA PEDROZA 